Research Paper

\title{
A Comparison of Minimally Invasive Video-Assisted Parathyroidectomy and Traditional Parathyroidectomy for Parathyroid Adenoma
}

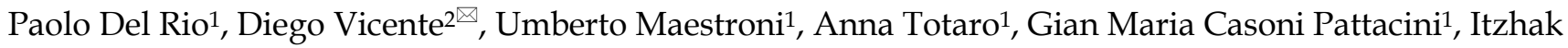
Avital $^{3}$, Alexander Stojadinovic ${ }^{2,4,5}$, Mario Sianesi ${ }^{1}$

1. Department of Surgery -University Hospital of Parma;

2. Department of Surgery, Walter Reed National Military Medical Center, Bethesda, MD, USA;

3. Bon Secours Cancer Institute, Richmond, VA, USA;

4. United States Military Cancer Institute, Bethesda, MD, USA;

5. Uniformed Services University of the Health Sciences, Bethesda, MD, USA.

$\square$ Corresponding author: Diego Vicente, tfelix@hjfresearch.org.

(C) Ivyspring International Publisher. This is an open-access article distributed under the terms of the Creative Commons License (http://creativecommons.org/ licenses/by-nc-nd/3.0/). Reproduction is permitted for personal, noncommercial use, provided that the article is in whole, unmodified, and properly cited.

Received: 2013.05.24; Accepted: 2013.06.18; Published: 2013.07.03

\begin{abstract}
Background: Pre-operative imaging techniques for sporadic primary hyperparathyroidism (SPHPT) and intraoperative parathyroid hormone (ioPTH) have led to the wide spread use of minimally invasive surgical approaches.

Study Design: In our prospectively collected database, 157 subjects with SPHPT and a preoperative diagnosis of parathyroid adenoma were treated with parathyroidectomy between January 2003 and November 20I I. Subjects in group A were enrolled between January 2003 to September 2006, and underwent traditional parathyroidectomy with intraoperative frozen section and bilateral neck exploration. Subjects in group B were enrolled between September 2006 to November 20II, and underwent minimally invasive video-assisted parathyroidectomy (MIVAP) with ioPTH. Operative times and post-operative pain levels were compared between groups. Subjects were followed for a minimum of 6 months post-operatively and recurrence rates and complication rates were measured between groups.

Results: 81 subjects were enrolled in group A, and 76 subjects were enrolled in group $B$. Pre-operative evaluation demonstrated that the groups were statistically similar. Significantly decreased operative times (28min vs. $62 \mathrm{~min}$ ) and post-operative pain levels were noted in group B. Recurrence rates were similar between group $A(3.7 \%)$ and group $B(2.6 \%)$.

Conclusions: MIVAP with ioPTH demonstrated significantly improved operative times and post-operative pain levels, while maintaining equivalent recurrence rates.
\end{abstract}

Key words: Parathyroidectomy, minimally invasive surgical approach

\section{Background}

Primary hyperparathyroidism is a hypercalcemic syndrome caused by excessive secretion of parathyroid hormone from a single adenoma in the majority $(75 \%)$ of cases ${ }^{1}$. The symptoms of hyperparathyroidism have been typically been associated with bone, renal, psychiatric, and gastrointestinal manifestations. While management of symptomatic patients is well established, prompt surgical management in asymptomatic patients has been suggested given the increased risk of cardiovascular disease ${ }^{2}$, as 
well as various cancers including hematopoietic malignancies, endocrine malignancies, gastrointestinal malignancies, renal cell carcinoma, squamous cell carcinoma, and breast cancer-5. For breast cancer, in particular, pre-diagnostic serum calcium levels have been positively associated with tumor aggressiveness ${ }^{6}$.

Traditional treatment approaches for sporadic primary hyperparathyroidism patients boast excellent cure rates and low complication rates, and include an anterior cervicotomy and bilateral neck exploration (BNE) with intraoperative identification and removal of the pathologic parathyroid gland. Advances in imaging techniques have led to pre-operative localization, which has allowed for minimally invasive targeted surgical approaches in cases of a single adenoma. Imaging with sonography and scintigraphy scans have demonstrated $85 \%$ and $90 \%$ sensitivities in identifying hyperfunctioning parathyroid glands of patients, respectively 7,8 . Concordant results of both studies correctly identified the single adenoma in 95\% of cases ${ }^{9}$. The development of intraoperative parathyroid hormone (ioPTH) has allowed for evaluation of cure upon removal of the suspected gland ${ }^{10-13}$, with long term cure rates as high as $99 \% 14,15$.

Using these methods, patients with pre-operatively localized glands benefited from a targeted open approach -Open Minimally Invasive Parathyroidectomy (OMIP)- with small incisions ${ }^{16}$ and minimal dissection to successfully remove the suspicious gland ${ }^{14,17-20}$. This allowed for decreased operative times and improved cosmetic outcomes 21 compared with traditional parathyroidectomy, while maintaining low recurrence rates with the use of ioPTH $^{22,23}$. Given the minimal learning curve for OMIP for surgeons with traditional parathyroidectomy experience ${ }^{24}$, and its equivalent success rate, minimally invasive parathyroidectomy caught on quickly and by 2002 the majority of surgeons were performing OMIP in selected patients ${ }^{25}$.

Endoscopic adaptation ${ }^{26-28}$ of these minimally invasive procedures allowed for even smaller incisions ${ }^{29}$. These endoscopic techniques can be performed by gasless video-assisted methods, such as the minimally invasive video assisted parathyroidectomy (MIVAP) technique 29,30, or completely endoscopically, and through a variety of approaches to including cervical 27,28 , as well as axillary ${ }^{31}$, and breast $^{32}$ approaches.

In this study we retrospectively evaluated operative times, post-operative pain, complication rates, and recurrence rates in patients with SPHPT undergoing MIVAP with ioPTH and traditional parathyroidectomy with intraoperative frozen section and
BNE from our prospectively collected database.

\section{Methods}

From January 2003 to November 2011, data from subjects at the University Hospital of Parma with biochemically verified SPHPT localized to a single adenoma on pre-operative imaging (ultrasound scan [US] and scintigraphy with 99mTc-Sestamibi [MIBI]) was collected in our prospective database. These subjects were then divided into two groups per time period. Subjects in group A served as the historical control group and were enrolled between January 2003 and September 2006. These subjects underwent traditional parathyroidectomy with BNE and intra-operative frozen section. Subjects in group B were enrolled between September 2006 and November 2011 and underwent MIVAP with ioPTH. ioPTH was performed by taking venous samples at time zero (prior to anesthesia on morning of surgery), and at five and ten minutes after resection of the pathologic parathyroid gland. A drop of PTH $>50 \%$ intra-operatively was considered a cure.

Exclusion criteria for the MIVAP group included a pathologic gland $>3 \mathrm{~cm}$ in size on pre-operative imaging, family history of parathyroid disease, previous neck surgery, and clinical suspicion for a parathyroid carcinoma or an inflammatory thyroid condition.

Subject characteristics including age, gender, imaging and laboratory data were collected pre-operatively in our prospective database. Operative and post-operative data was recorded post-operatively in the database.

All subjects underwent pre-operative videolaryngostroboscopy (VLS), and VLS was repeated post-operatively if the subject or clinician were concerned for any voice changes. Operative times were recorded as the time from the incision to the placement of the dressing. Post-operative pain evaluations by visual analogue scale were performed post-operatively at 1 hour and 24 hours. Post-operative evaluation for cure of hyperparathyroidism included an at least 6 month follow up of $\mathrm{Ca}$ and PTH values with recurrence defined as Ca $>10.5 \mathrm{mg} / \mathrm{dL}$ and/or PTH $>72 \mathrm{pg} / \mathrm{mL}$.

\section{Results}

157 subjects, group A (81) and group B (76), were enrolled in our prospectively collected database and underwent parathyroidectomy by one of two experienced endocrine surgeons at our center, both previously trained in the traditional open technique as well as the MIVAP technique. The standard incision for the traditional cervicotomy for group A was $4 \mathrm{~cm}$ and for the MIVAP incision of group B was $2 \mathrm{~cm}$. Table 1 
demonstrates that group A and group B were similar in age $(p=0.83)$, and gender $(p=0.13)$. Parathyroid gland size was significantly larger in group A (1.8 vs. $1.2 \mathrm{~cm}, \mathrm{p}<0.05)$. Pre-operative calcium levels were higher in group B (11.1 vs 11.7, p = 0.018).

US and MIBI pre-operative imaging were performed on all subjects. Pathologic parathyroid glands were identified with pre-operative imaging with MIBI in $96 \%$ and $86 \%$ of subjects in groups $\mathrm{A}$ and $\mathrm{B}$, respectively. A suspicious parathyroid gland was identified by US in $65 \%$ of group A subjects and $64 \%$ of group B subjects. Concordant studies were demonstrated in $54 \%$ of group A and $55 \%$ group B subjects.

In this study we found eight subjects with thyroid goiters, 5 in group A and 3 in group B, which were diagnosed on US pre-operatively and these cases were treated with lobectomy through the MIVAP incision in group $\mathrm{B}$ and through traditional incision in group A.

Gland locations are described in table 2. Pathologic glands were most commonly identified in the inferior parathyroid glands in both groups, and one ectopic parathyroid gland was identified in group B as seen in Table 2. Video-assisted BNE was performed in three group B subjects due to failure to locate the suspicious parathyroid gland seen on pre-operative imaging, including one case in which an ectopic retro-esophageal parathyroid gland was found. The remaining two subjects had glands identified in the in- ferior right and superior right positions. These glands were successfully identified and removed with appropriate drop in ioPTH and without conversion to traditional cervicotomy.

Operative times, conversion from MIVAP to open technique rate, post-operative pain levels, and complication rates are described in table 3 . Operative times were significantly shorter ( 29 vs. $62 \mathrm{~min}, \mathrm{p}<0.05$ ) and post-operative pain levels were significantly lower in group B compared with group A. Post-operative calcium levels were similar between groups.

The ioPTH did not decrease in four MIVAP cases after removal of the pre-operatively identified parathyroid gland. When video-assisted BNE failed to identify a pathologic gland in these subjects, an open BNE was performed which revealed pathologic contralateral parathyroid glands. Resection of this second gland resulted in a corresponding, appropriate decrease in PTH.

Three cases of primary hyperparathyroidism relapsed in group A and two cases in group B. These subjects underwent traditional cervicotomy and re-exploration with removal of a pathologic parathyroid gland and appropriate drop in PTH. One subject from each group developed dysphonia post-op with VLS demonstrating unilateral vocal fold paralysis, and these subjects were referred to speech therapy.

Table I: Pre-operative characteristics of subjects undergoing traditional parathyroidectomy with intra-operative frozen section (group A) and minimally invasive video- assisted parathyroidectomy with intra-operative PTH.

\begin{tabular}{|c|c|c|c|c|c|}
\hline \multirow[t]{2}{*}{ Pre-Operative Characteristics } & \multicolumn{2}{|c|}{$A(n=81)$} & \multicolumn{2}{|c|}{$B(n=76)$} & \multirow[b]{2}{*}{$\mathrm{p}$} \\
\hline & $\mathrm{n}(\%)$ & Mean+/-SD & $\mathrm{n}(\%)$ & Mean+/-SD & \\
\hline Age (year) & & $60.34+/-10.43$ & & $59.76+/-14.32$ & 0.83 \\
\hline Gender (Female:Male) & $64(79 \%): 17(21 \%)$ & & $67(88 \%): 9(12 \%)$ & & 0.13 \\
\hline Pre-Operative Calcium (mg/dL) & & $11.1+/-0.4$ & & $11.7+/-0.6$ & 0.018 \\
\hline MIBI & $78(96 \%)$ & & $65(86 \%)$ & & 0.24 \\
\hline US & $53(65 \%)$ & & $49(64 \%)$ & & $>0.99$ \\
\hline MIBI and US & $44(54 \%)$ & & $42(55 \%)$ & & $>0.99$ \\
\hline Adenoma Size (cm) & & $1.8+/-0.3$ & & $1.2+/-0.2$ & $<0.05$ \\
\hline Thyroid Goiter & $5(6 \%)$ & & $3(4 \%)$ & & 0.72 \\
\hline
\end{tabular}

Table 2: Parathyroid gland location for group A and group B. Ectopic parathyroid gland found in the retro-esophageal position.

\begin{tabular}{llll}
\hline Primary Parathyroid Gland location & Group A & Group B & p \\
\hline Right Superior & $13(16 \%)$ & $4(5 \%)$ & $<0.05$ \\
Right Inferior & $26(32 \%)$ & $24(31 \%)$ & $>0.99$ \\
Left Superior & $8(10 \%)$ & $15(20 \%)$ & 0.11 \\
Left Inferior & $34(42 \%)$ & $33(43 \%)$ & 0.87 \\
Ectopic & 0 & $1(1 \%)$ & $<0.05$ \\
\hline
\end{tabular}


Table 3: Operative times, post-operative pain levels, and complication rates compared between group A and group B. MIVAP BNE failed to identify a pathologic parathyroid gland in 4 subject in Group B. These cases were converted to traditional open parathyroidectomy procedure and the pathologic parathyroid glands were identified and removed with appropriate drop in ioPTH.

\begin{tabular}{|c|c|c|c|c|c|c|}
\hline \multirow[t]{2}{*}{ Operative Outcomes } & & \multicolumn{2}{|c|}{ Group A } & \multicolumn{2}{|c|}{ Group B } & \multirow[b]{2}{*}{$\mathrm{p}$} \\
\hline & & $\mathrm{n}(\%)$ & Mean+/-SD & $\mathrm{n}(\%)$ & Mean+/-SD & \\
\hline Operative times (min) & & & $62.4+/-26.5$ & & $29.0+/-7.9$ & $<0.001$ \\
\hline Conversion to traditional bilateral neck exploration & & - & & $4(5 \%)$ & & - \\
\hline Post-operative pain & @ 1 hour & & $2.6+/-0.6$ & & $1.4+/-0.4$ & $<0.001$ \\
\hline & @ 24 hour & & $3.6+/-0.5$ & & $2.1+/-0.6$ & $<0.001$ \\
\hline Post-operative Calcium (mg/dL) & @ 6 month & & $8.9+/-0.8$ & & $8.3+/-0.9$ & 0.09 \\
\hline Relapse & @ 6 month & $3(3.7 \%)$ & & $2(2.63 \%)$ & & $>0.99$ \\
\hline Post-operative Dysphonia & & $1(1 \%)$ & & $1(1 \%)$ & & $>0.99$ \\
\hline
\end{tabular}

\section{Discussion}

Minimally invasive parathyroid surgery has become the preferred technique for the majority of surgeons treating patients with SPHPT ${ }^{25,33}$. In general, the indications for minimally invasive parathyroidectomy for SPHPT patients include no history of cervical exploration and presence of a single pathologic parathyroid gland smaller than $3 \mathrm{~cm}$ located in one of the standard locations on pre-operative imaging without concomitant thyroid disease ${ }^{34-36}$.

Of the minimally invasive options for parathyroidectomy, MIVAP offers several advantages in that it resembles traditional parathyroidectomy in technique thereby allowing the surgeon to perform a BNE $^{34,37-39}$ while maintaining a small $(1.5-2.0 \mathrm{~cm})$ cervicotomy and allowing for prompt identification of the recurrent laryngeal nerves and parathyroid glands with endoscopically enhanced magnification ${ }^{35,38}$. This permits broader indications for minimally invasive treatment of SPHPT including those cases of multiglandular disease.

In this retrospective review of our prospectively collected database comparing traditional parathyroidectomy with intra-operative frozen section and MIVAP with ioPTH, we have added to a growing body of evidence which demonstrates significantly decreased post-operative pain and shorter operative times with MIVAP ${ }^{40,41}$.

Being able to avoid neck hyperextension and less tissue dissection in the video-assisted and targeted approach likely contributes to the decreased pain levels in MIVAP patients ${ }^{36}$. The decrease in post-operative pain has also been demonstrated when comparing MIVAP to OMIP38,42,43. The results comparing mean operative times between MIVAP and
OMIP in the literature are mixed with either equivalent (44 vs. $49 \mathrm{~min})^{38}$ or longer ( 84 vs. $\left.60 \mathrm{~min}\right)^{42}$ operative times in the MIVAP group. It is important to note, however, that several studies have demonstrated that MIVAP operative times improve significantly with surgeon experience ${ }^{34,37,44}$, with mean MIVAP operative times in experienced hands as low as 28 minutes ${ }^{37}$, similar to this study.

Given the long term risks of cardiovascular disease $^{2}$ and malignancy ${ }^{3-5}$ associated with hyperparathyroidism, our group performs evaluation for cure of disease in our patients at 6 months post-operatively with serum calcium and parathyroid hormone evaluations. In this study, most subjects returned to normal serum calcium at this time point with low relapse rates in both group A $(3.7 \%)$ and group B $(2.6 \%)$ subjects. These rates are comparable to other studies in the literature which have reported cure rates of patients with SPHPT treated with MIVAP to be greater than $98 \%$ with long-term follow up 34,36 .

The excellent cure rates associated with MIVAP have been attributed to a combination of appropriate patient selection with pre-operative imaging, the use of ioPTH for evaluation of cure, and the ability to perform video-assisted BNE when the suspected adenoma cannot be identified or when there is concern for multiglandular disease $\mathrm{e}^{36,39,45}$. In the absence of ioPTH or presence of questionable ioPTH results, MIVAP with video-assisted BNE has actually been demonstrated to be as effective in treating SPHPT as MIVAP with ioPTH with similar operative times ${ }^{46}$.

The ability to perform video-assisted BNE during MIVAP also contributes to the low conversion rates seen in this study and other MIVAP studies $^{34,36,39}$. All four subjects that underwent conversion to traditional cervicotomy and BNE did so after an 
inappropriate decrease in ioPTH after removal of pre-operatively identified adenoma and failed video-assisted BNE. A pathologic gland was identified and removed from the contralateral side with an appropriate drop in ioPTH. Three subjects in the MIVAP group underwent video-assisted BNE due to failed identification of a pathologic gland at the pre-operatively identified location. Successful video-assisted BNE revealed two subjects with pathologic glands in the standard locations and a third subject with a pathologic gland in the retro-esophageal position. In this study, and one other study ${ }^{35}$, MIVAP allowed for localization and removal of the ectopic gland through the minimally invasive cervicotomy.

As previously described in the literature, thyroid diseases -specifically goiters- are endemic to our demographic population 7,34,36. These goiters have been effectively treated concurrently with the SPHPT through the MIVAP incision in our study and similar studies $^{34,36}$. The capacity to treat associated thyroid goiters allows for a broader set of indications for minimally invasive parathyroid surgery with MIVAP compared to other minimally invasive techniques.

Despite a significant learning curve and surgeon experience determined outcomes ${ }^{37}$, all of the benefits presented above have led to MIVAP being readily applied in referral centers $36-38,47$. Of note though, traditional parathyroidectomy with BNE continues to be the most common operation for SPHPT in some parts of the world ${ }^{9}$, and continues to be an essential tool in the treatment of parathyroid disease.

Despite the excellent cure rates with MIVAP and targeted exploration with pre-operative imaging and confirmation of cure with ioPTH presented in the literature and in this study, several authors have also demonstrated that ioPTH may not be as reliable as we had initially hoped in ruling out multiglandular disease $^{48}$, particularly when only a $50 \%$ drop in ioPTH at 10 minutes is used as the confirmation of cure ${ }^{49}$.

Further, a recent publication based on a large trial argues that we should do away with unilateral exploration for the treatment of SPHPT ${ }^{50}$. The proposed technique in this study includes an open minimally invasive length cervicotomy ${ }^{16}$, pre-operative MIBI scan, BNE for all patients regardless of pre-operative imaging results, and intraoperative radioactive counts to confirm that non-dormant glands are excised. The reported mean operative time for this procedure is 22 minutes.

While this technique has been hailed as the parathyroid surgery of the future ${ }^{51}$, there may still be room for MIVAP, particularly MIVAP with BNE, given that comparative studies between OMIP and
MIVAP have demonstrated improved post-operative pain and patient satisfaction with cosmesis with MIVAP over OMIP14. Further, a trial demonstrating the generalizability of this new technique to multiple centers and how it compares to other minimally invasive parathyroidectomy procedures is still pending.

\section{Competing Interests}

The authors have declared that no competing interest exists.

\section{References}

1. Norman J, Goodman A, Politz D. Calcium, parathyroid hormone, and vitamin $\mathrm{D}$ in patients with primary hyperparathyroidism: normograms developed from 10,000 cases. Endocr Pract 2011;17: 384-94.

2. Piovesan A, Molineri N, Casasso F, Emmolo I, Ugliengo G, Cesario F, Borretta G. Left ventricular hypertrophy in primary hyperparathyroidism. Effects of successful parathyroidectomy. Clin Endocrinol (Oxf) 1999;50: 321-8.

3. Nilsson IL, Zedenius J, Yin L, Ekbom A. The association between primary hyperparathyroidism and malignancy: nationwide cohort analysis on cancer incidence after parathyroidectomy. Endocrine-related cancer 2007;14: 135-40.

4. Pickard AL, Gridley G, Mellemkjae L, Johansen C, Kofoed-Enevoldsen A, Cantor KP, Brinton LA. Hyperparathyroidism and subsequent cancer risk in Denmark. Cancer 2002;95: 1611-7.

5. Almquist M, Manjer J, Bondeson L, Bondeson AG. Serum calcium and breast cancer risk: results from a prospective cohort study of 7,847 women. Cancer causes \& control : CCC 2007;18: 595-602.

6. Almquist M, Anagnostaki L, Bondeson L, Bondeson AG, Borgquist S, Landberg G, Malina J, Malm J, Manjer J. Serum calcium and tumour aggressiveness in breast cancer: a prospective study of 7847 women. European journal of cancer prevention : the official journal of the European Cancer Prevention Organisation 2009;18: 354-60.

7. Mazzeo S, Caramella D, Lencioni R, Molea N, De Liperi A, Marcocci C, Miccoli P, Iacconi P, Bossio GB, Viacava P, Lazzeri E, Bartolozzi C. Comparison among sonography, double-tracer subtraction scintigraphy, and double-phase scintigraphy in the detection of parathyroid lesions. AJR Am J Roentgenol 1996;166: 1465-70.

8. Denham DW, Norman J. Cost-effectiveness of preoperative sestamibi scan for primary hyperparathyroidism is dependent solely upon the surgeon's choice of operative procedure. J Am Coll Surg 1998;186: 293-305.

9. Bergenfelz A, Jansson S, Martensson H, Reihner E, Wallin G, Kristoffersson A, Lausen I. Scandinavian Quality Register for Thyroid and Parathyroid Surgery: audit of surgery for primary hyperparathyroidism. Langenbecks Arch Surg 2007;392: 445-51.

10. Lee JA, Inabnet WB, 3rd. The surgeon's armamentarium to the surgical treatment of primary hyperparathyroidism. J Surg Oncol 2005;89: 130-5.

11. Irvin GL, 3rd, Solorzano CC, Carneiro DM. Quick intraoperative parathyroid hormone assay: surgical adjunct to allow limited parathyroidectomy, improve success rate, and predict outcome. World J Surg 2004;28: 1287-92.

12. Inabnet WB. Intraoperative parathyroid hormone monitoring. World J Surg 2004;28: 1212-5.

13. Bergenfelz AO, Hellman P, Harrison B, Sitges-Serra A, Dralle H, European Society of Endocrine S. Positional statement of the European Society of Endocrine Surgeons (ESES) on modern techniques in pHPT surgery. Langenbecks Arch Surg 2009;394: 761-4.

14. Barczynski M, Konturek A, Cichon S, Hubalewska-Dydejczyk A, Golkowski F, Huszno B. Intraoperative parathyroid hormone assay improves outcomes of minimally invasive parathyroidectomy mainly in patients with a presumed solitary parathyroid adenoma and missing concordance of preoperative imaging. Clin Endocrinol (Oxf) 2007;66: 878-85.

15. Maweja S, Sebag F, Hubbard J, Giorgi R, Henry JF. Immediate and medium-term results of intraoperative parathyroid hormone monitoring during video-assisted parathyroidectomy. Arch Surg 2004;139: 1301-3.

16. Brunaud L, Zarnegar R, Wada N, Ituarte P, Clark OH, Duh QY. Incision length for standard thyroidectomy and parathyroidectomy: when is it minimally invasive? Arch Surg 2003;138: 1140-3. 
17. Udelsman R, Donovan PI, Sokoll LJ. One hundred consecutive minimally invasive parathyroid explorations. Ann Surg 2000;232: 331-9.

18. Agarwal G, Barraclough BH, Reeve TS, Delbridge LW. Minimally invasive parathyroidectomy using the 'focused' lateral approach. II. Surgical technique. ANZ J Surg 2002;72: 147-51.

19. Inabnet WB, 3rd, Dakin GF, Haber RS, Rubino F, Diamond EJ, Gagner M. Targeted parathyroidectomy in the era of intraoperative parathormone monitoring. World J Surg 2002;26: 921-5.

20. Udelsman R. Six hundred fifty-six consecutive explorations for primary hyperparathyroidism. Ann Surg 2002;235: 665-70; discussion 70-2.

21. Norman J, Chheda H, Farrell C. Minimally invasive parathyroidectomy for primary hyperparathyroidism: decreasing operative time and potential complications while improving cosmetic results. Am Surg 1998;64: 391-5; discussion 5-6.

22. Westerdahl J, Bergenfelz A. Unilateral versus bilateral neck exploration for primary hyperparathyroidism: five-year follow-up of a randomized controlled trial. Ann Surg 2007;246: 976-80; discussion 80-1.

23. Russell CF, Dolan SJ, Laird JD. Randomized clinical trial comparing scan-directed unilateral versus bilateral cervical exploration for primary hyperparathyroidism due to solitary adenoma. Br I Surg 2006;93: 418-21.

24. Soon PS, Yeh MW, Sywak MS, Roach P, Delbridge LW, Sidhu SB. Minimally invasive parathyroidectomy using the lateral focused miniincision approach: Is there a learning curve for surgeons experienced in the open procedure? J Am Coll Surg 2007;204: 91-5.

25. Sackett WR, Barraclough B, Reeve TS, Delbridge LW. Worldwide trends in the surgical treatment of primary hyperparathyroidism in the era of minimally invasive parathyroidectomy. Arch Surg 2002;137: 1055-9.

26. Gagner M. Endoscopic subtotal parathyroidectomy in patients with primary hyperparathyroidism. Br J Surg 1996;83: 875.

27. Yeung $\mathrm{GH}, \mathrm{Ng} \mathrm{JW}$. The technique of endoscopic exploration for parathyroid adenoma of the neck. Aust N Z J Surg 1998;68: 147-50.

28. Cougard P, Goudet P, Bilosi M, Peschaud F. [Videoendoscopic approach for parathyroid adenomas: results of a prospective study of 100 patients]. Ann Chir 2001;126: 314-9.

29. Miccoli P, Bendinelli C, Conte M, Pinchera A, Marcocci C. Endoscopic parathyroidectomy by a gasless approach. J Laparoendosc Adv Surg Tech A 1998;8: 189-94.

30. Miccoli P, Bendinelli C, Vignali E, Mazzeo S, Cecchini GM, Pinchera A, Marcocci C. Endoscopic parathyroidectomy: report of an initial experience. Surgery 1998;124: 1077-9; discussion 9-80.

31. Ikeda Y, Takami H, Sasaki Y, Takayama J, Niimi M, Kan S. Clinical benefits in endoscopic thyroidectomy by the axillary approach. J Am Coll Surg 2003;196: 189-95.

32. Ikeda Y, Takami H, Niimi M, Kan S, Sasaki Y, Takayama J. Endoscopic total parathyroidectomy by the anterior chest approach for renal hyperparathyroidism. Surg Endosc 2002;16: 320-2.

33. Greene AB, Butler RS, McIntyre S, Barbosa GF, Mitchell J, Berber E, Siperstein A, Milas M. National trends in parathyroid surgery from 1998 to 2008: a decade of change. J Am Coll Surg 2009;209: 332-43.

34. Miccoli P, Berti P, Materazzi G, Massi M, Picone A, Minuto MN. Results of video-assisted parathyroidectomy: single institution's six-year experience. World J Surg 2004;28: 1216-8.

35. Bellantone R, Raffaelli M, C DEC, Traini E, Lombardi CP. Minimally-invasive parathyroid surgery. Acta Otorhinolaryngol Ital 2011;31: 207-15.

36. Lombardi CP, Raffaelli M, Traini E, De Crea C, Corsello SM, Sollazzi L, Pontecorvi A, Bellantone R. Advantages of a video-assisted approach to parathyroidectomy. ORL J Otorhinolaryngol Relat Spec 2008;70: 313-8.

37. Berti P, Raffaelli M, Materazzi G, Galleri D, Miccoli P. [Video-assisted parathyroidectomy: learning curve]. Ann Chir 2001;126: 772-6.

38. Barczynski M, Cichon S, Konturek A, Cichon W. Minimally invasive video-assisted parathyroidectomy versus open minimally invasive parathyroidectomy for a solitary parathyroid adenoma: a prospective, randomized, blinded trial. World J Surg 2006;30: 721-31.

39. Alesina PF, Singaporewalla RM, Walz MK. Video-assisted bilateral neck exploration in patients with primary hyperparathyroidism and failed localization studies. World J Surg 2010;34: 2344-9.

40. Miccoli P, Bendinelli C, Berti P, Vignali E, Pinchera A, Marcocci C. Video-assisted versus conventional parathyroidectomy in primary hyperparathyroidism: a prospective randomized study. Surgery 1999;126: 1117-21; discussion 21-2.

41. Miccoli P, Barellini L, Monchik JM, Rago R, Berti PF. Randomized clinical trial comparing regional and general anaesthesia in minimally invasive video-assisted parathyroidectomy. Br J Surg 2005;92: 814-8.

42. Hessman O, Westerdahl J, Al-Suliman N, Christiansen P, Hellman P, Bergenfelz A. Randomized clinical trial comparing open with video-assisted minimally invasive parathyroid surgery for primary hyperparathyroidism. Br J Surg 2010;97: 177-84.

43. Lombardi CP, Raffaelli M, Traini E, De Crea C, Corsello SM, Bellantone R. Video-assisted minimally invasive parathyroidectomy: benefits and long-term results. World J Surg 2009;33: 2266-81.

44. Del Rio P, Bezer L, Palladino S, Arcuri MF, Iotti E, Sianesi M. Operative time and postoperative pain following minimally invasive video-assisted parathyroidectomy. G Chir 2010;31: 155-8.

45. Miccoli P, Berti P, Conte M, Raffaelli M, Materazzi G. Minimally invasive video-assisted parathyroidectomy: lesson learned from 137 cases. J Am Coll Surg 2000;191: 613-8.

46. Miccoli P, Berti P, Materazzi G, Ambrosini CE, Fregoli L, Donatini G. Endoscopic bilateral neck exploration versus quick intraoperative parathormone assay (qPTHa) during endoscopic parathyroidectomy: A prospective randomized trial. Surg Endosc 2008;22: 398-400.

47. Lorenz K, Miccoli P, Monchik JM, Duren M, Dralle H. Minimally invasive video-assisted parathyroidectomy: multiinstitutional study. World J Surg 2001;25: 704-7.

48. Siperstein A, Berber E, Barbosa GF, Tsinberg M, Greene AB, Mitchell J, Milas M. Predicting the success of limited exploration for primary hyperparathyroidism using ultrasound, sestamibi, and intraoperative parathyroid hormone: analysis of 1158 cases. Ann Surg 2008;248: 420-8.

49. Karakousis GC, Han D, Kelz RR, Nemani D, Karamacharya J, Roses R, Gimotty PA, Fraker DL. Interpretation of intra-operative PTH changes in patients with multi-glandular primary hyperparathyroidism (pHPT). Surgery 2007;142: 845-50.

50. Norman J, Lopez J, Politz D. Abandoning unilateral parathyroidectomy: why we reversed our position after 15,000 parathyroid operations. J Am Coll Surg 2012;214: 260-9.

51. Stojadinovic A, Pribitkin E, Rosen D, Edwards M, Byrd DR. Unilateral vs bilateral parathyroidectomy: a healthy debate. J Am Coll Surg 2012;215: $300-2$. 